\title{
Naturalismo e Design: da Mão à Colher
}

\author{
Naturalism and design:
}

the hand to spoon

\begin{abstract}
por Bruna Brogin, Richard Perassi Luiz de Souza, Sharlene Melanie, Túlio Henrique Mandolesi Sá e Vilson João Batista
\end{abstract}

\section{RESUMO}

Neste artigo, procura-se evidenciar como ocorre o processo de interação do ser humano com a natureza, a fim de solucionar os problemas da vida como, por exemplo, a necessidade de comer. Esse processo acontece naturalmente através dos anos, da evolução do homem e da maneira como ele age e estuda os sistemas naturais, desenvolvendo o design como um processo natural de sua própria evolução. A "coIher" é o objeto tecnológico em estudo. Sendo que, primeiramente, este estudo foi desenvolvido como pesquisa exploratória. Em seguida, foi proposta a classificação dos temas que permeiam este artigo como: Naturalismo, Design e História. Os resultados informam sobre a construção da percepção e da prática humana, a partir de seu convívio com a natureza e de sua capacidade natural de desenvolver técnicas e modelos abstratos, tipicamente culturais.

Palavras-chave: biônica; observação da natureza; utensílio de comer

\section{ABSTRACT}

In this article, we seek to show how the process occurs in human interaction with nature, in order to solve the problems of life, for example, the need to eat. This process happens naturally through the years, the evolution of man and the way he acts and studying natural systems, developing design as a natural process of their own evolution. The "spoon" is the technological object under study. Being that, first, this study was designed as an exploratory research. Then it was proposed the classification of themes that permeate this article as: Naturalism, Design and History. The results provide information about the construction of perception and human practice, from their interaction with nature and their natural ability to develop technical and abstract models, typically cultural.

Keywords: bionic; nature watching; eating utensil 


\section{INTRODUÇÃO}

0 Design é a interface adaptativa do novo, ele cria e desenvolve projetos de adaptação ou de inserção na moda e na cultura. Sua adaptabilidade envolve questões como cognição, idealismo, funcionalidade, pragmatismo, ordenação lógica, mensuração, projeto, ergonomia, tecnologia, produtividade e sustentabilidade.

A adaptabilidade também constitui aspectos centrais do estudo da biologia, pois uma das maiores características que os organismos vivos possuem é a de se adequarem ao ambiente, conquistando sua sobrevivência. A disciplina que junta o design e a biologia é conhecida como Biônica, inspirações da natureza.

Para Munari (2008, p. 330), Biônica estuda os sistemas vivos, ou semelhantes aos vivos, para descobrir processos, técnicas e novos princípios aplicáveis a tecnologia. Examina os princípios, as características e os sistemas com transposição de matéria, com extensão de comandos, com transferência de energia e de informação. Toma-se como ponto de partida um fenômeno natural e, a partir daí, pode-se desenvolver uma solução de projeto. Segundo Costa et al. (2010) é uma área que se organizou a partir de uma possibilidade difícil de ser explicada, ou seja, a possibilidade experimentada pelos seres humanos de conhecer os sistemas naturais e aplicar esse conhecimento no avanço dos processos culturais.

Se a etimologia da palavra saber (derivada do latim sapere, "ter gosto, sentir gosto") é sabor, então significa ter a experiência a partir das sensações e intuições. A Biônica pode ser então considerada como o saber da natureza, pois a compreensão dos sistemas naturais se dão devido a experiência.

A concepção filosófica que aborda esses conceitos é o Naturalismo, considerando o desenvolvimento do processo cognitivo em decorrência evolutiva da natureza e modelo evolutivo para a cultura.

Entre as metodologias e abordagens de pesquisa, o naturalista pode e deve ser considerado buscando soluções que aproximem os objetos de design dos sistemas naturais, concebendo-os como uma extensão do ser humano e parte integrante do ambiente natural (PATARRNA, 2003).

0 objetivo geral deste artigo é demonstrar como o processo de evolução dos produtos da raça humana acontece naturalmente e de que forma o design participa nesta evolução. 0 objeto de estudo escolhido foi a colher, utensílio corriqueiro do dia a dia que veio substituir a ação do homem que antigamente utilizava a mão para comer e beber, adaptando o formato da mão e dos dedos como a de uma concha. Em algum momento do passado, os ancestrais pararam de utilizar as mãos e descobriram que utilizando esta ferramenta, poderiam mais facilmente sorver líquidos sem o uso das mãos, principalmente os líquidos quentes. Essa atitude natural pode ter caracterizado e influenciado o formato atual da colher. 


\section{PROCEDIMENTOS METODOLÓGICOS}

Para elaboração deste artigo foi realizado uma pesquisa exploratória sobre filosofia com enfoque no Naturalismo, bem como estudo de biônica, design e produtos, buscando a história de artefatos para culinária, com enfoque na colher, e sua origem na observação da natureza. Foram usados livros conhecidos sobre os assuntos abordados, bem como artigos como pesquisa recentes nos temas.

Segundo Lakatos e Marconi (2007) este artigo possui metodologia classificatória, pois se buscou classificar os assuntos que permeiam o Naturalismo, o design, e a história da colher como elemento que faz o elo entre o design e o Naturalismo por meio da observação humana e adaptação por meio de semelhança, seguindo conceitos da biônica. A partir das classificações são feitos elos que integram um conceito ao outro a fim de se obter uma conclusão sobre os problemas deste artigo.

\section{NATURALISMO E BIÔNICA}

Segundo o Dicionário Básico de Filosofia (JAPIASSÚ e MARCONDES, 2001), Naturalismo é uma concepção filosófica que não admite a existência de nada que seja exterior à natureza, reduzindo o conceito de realidade à experimentação do mundo natural. 0 naturalismo recusa, portanto, qualquer elemento sobrenatural ou princípio transcendente.

Dutra (2005) afirma que Quine (séc. XX) defendia em seu Artigo “Epistemologia Naturalizada" que a epistemologia deve ser praticada de maneira naturalizada. Que deve levar em consideração os processos psicológicos e psicolinguísticos. Ele partia da ideia de que o conhecimento tem início em algum tipo de experiência, em uma estimulação sensorial. Os 05 sentidos seriam a entrada (o input) de todos os dados vindos do ambiente físico externo que seriam processados e transformados em experiências. Porém, Hume pregava que todo conhecimento humano provinha da observação do mundo a sua volta, sejam coisas, processos ou acontecimentos, sendo que o próprio pensamento seria algo natural do ser humano.

Segundo Costa et al. (2010), o método de buscar analogias na natureza é o que mais aproxima a Biônica da filosofia naturalista, já que essa corrente propõe que o conhecimento é construído por associação de ideias. Hume afirma que há três maneiras pelas quais se associam as ideias:

- Causa e efeito:

0 velcro pode ser considerado uma associação de causa e efeito porque, na natureza, duas superfícies com um determinado tipo de textura tendem a aderir uma na outra (Fig. 1). 


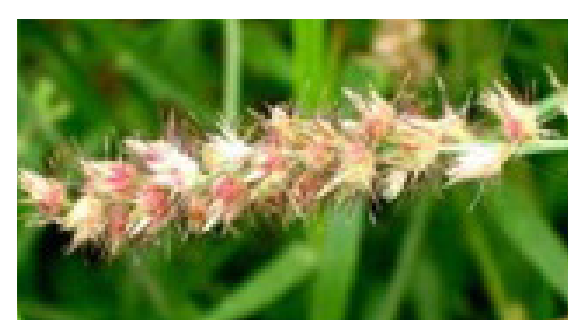

2.

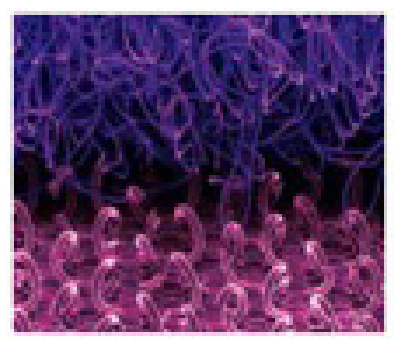

3.

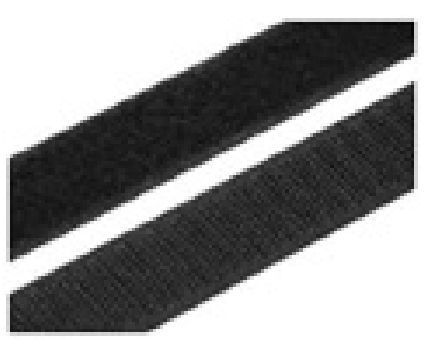

Fig. 1: Velcro como representação da associação de causa e efeito.

Fonte: (1) Disponível em: http://www.sidneyrezende.com/noticia/160880+carrapicho+pode+ser+nova+solucao+para+acabar+com+as+rugas

(2) Disponível em: http://patycichelli.blogspot.com.br/2012/11/5-grandes-invencoes-e-seus-criadores. html

(3) Disponível em: http://www.stoklasa-eu.com/hook-and-loop-fasteners-velcro-x2S01126

- Contiguidade:

A representação da associação por contiguidade pode ser dita pelo design básico de um helicóptero, com relação ao animal libélula (Fig 2), porque houve a adaptação direta de um sistema natural para um produto cultural, que é percebida na analogia com as formas das asas e, mais especificamente, na reprodução de sua capacidade de voar em espiral, devido ao funcionamento de hélices.

1.

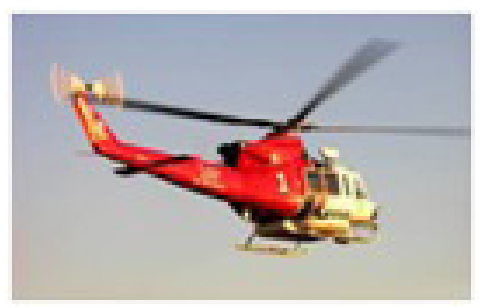

2.

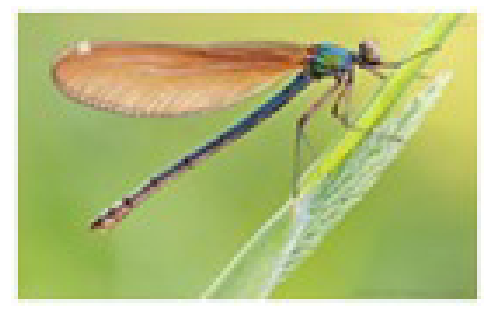

Fig. 2: Helicóptero como representação da associação por contiguidade.

Fonte: (1) Disponível em: http://www.top-walls.com/wallpaper/los-angeles-city-fire-department-helicopter/

(2) Disponivel em: http://www.wallsforpc.com/wallpaper/dragonfly-2/

- Semelhança:

Pode ser exemplificada como as formas aerodinâmicas que serviram de modelo para 0 carro conceito Biônico da marca Mercedes-Benz (Fig. 3), projetado a partir de associações por semelhança da forma de um espécie de peixe, planta e esqueleto. 


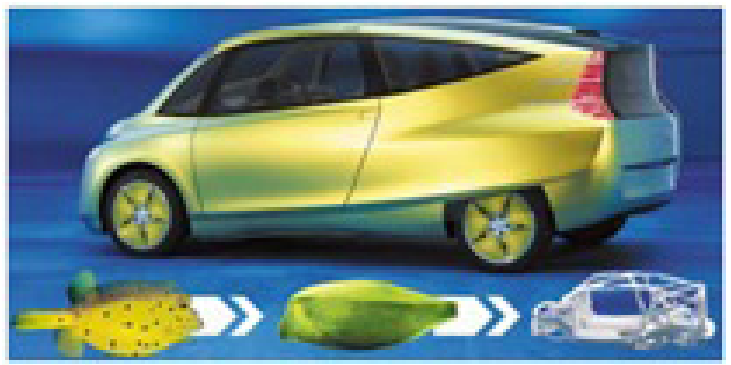

Fig. 3: Mercedes-Benz como modelo de associação por semelhança.

Fonte: Disponível em: http://quatrorodas.abril.com.br/reportagens/novastecnologias/conteudo_189599. shtml

A corrente filosófica naturalista considera o desenvolvimento do processo cognitivo como decorrência evolutiva da natureza. Portanto, adquirir conhecimento é um fenômeno natural baseado em observações. E estas por sua vez gerariam os hábitos e os costumes.

Termos como Biomimética, Biônica e Biodesign têm sido usados constantemente para identificar os estudos realizados através de questões empíricas baseadas nos parâmetros da natureza. Alguns os diferenciam, mas todos possuem bases etimológicas parecidas. 0 conceito de Biomimética, do grego bios ("vida") e mimesis ("imitação"), foi proposto pelo Engenheiro Biomédico Otton Schumtt (1950), significando uma ciência que possui uma visão para além de analogias de propriedades mecânicas dos produtos com os sistemas viventes (BENYUS, 2010). Já a palavra Bionic ou Biônica, criada pelo pesquisador Jack Steele (1960), nasceu da união do prefixo Bio ("vida"), com o sufixo ic ("como" ou "pertencente a"), correspondendo à "pertencente à vida", "como a vida" ou "da maneira da vida" (OLIVEIRA, 2012). E Biodesign é um termo dito por Luigi Colani, defendendo a natureza como um farol para orientar o seu trabalho, e o curvo, o redondo, o orgânico vão sempre se manifestar para dar corpo à esse método, é uma adaptação dos conceitos de Biomimética ao Design (BATISTA, 2013).

Conclui-se que Biomimética, Biônica e Biodesign são todas ciências que se preocupam com o estudo dos elementos da natureza para o aprendizado humano. Podem ser consideradas ciência multidisciplinares, pois trabalha em áreas como administração, design, engenharia, arquitetura, medicina, biologia, etc. Essas áreas se relacionam para resultar em um sistema mais eco-eficiente, economicamente viável e que incluam as demais vertentes dentro da sustentabilidade.

0 Biomimetismo também possui em seu contexto os exemplos citados anteriormente, como o velcro inspirado na semente do Arctium, vai-se tornando assim num biodesign, no sentido do design vivo: moléculas, células, tecidos, órgãos, corpos inteiros, deixaram de ser produtos exclusivos da natureza, para se tornarem artefatos criados pela ação humana. Num contexto em que as fronteiras entre o natural e 0 artificial também se desvanecem. Neste panorama, a biotecnologia veio transformar a forma como se entende a vida, gerando novos campos de estudo, aplicação, design e engenharia determinados pelo biológico e pelo genético. 0 Biodesign se dedica à modificação e criação de organismos, quer numa perspectiva de melhoramento de qualidades, quer para fabricação ou manipulação de outros organismos (MOURA, 2011). 
Segundo Costa et al. (2010), na perspectiva do movimento filosófico Naturalismo, como sistema vivo, o próprio ser humano é regido pela natureza e o conhecimento decorre de um processo complexo, e igualmente natural, que não pode ser explicado pela lógica idealista.

0 Naturalismo defende que deve haver uma mediação entre esta entrada e a saída das sensações pelo ser humano. Segundo Quine, a diferença entre a pobreza da entrada sensorial (input) e a riqueza da saída (output) é a descrição detalhada, consistente e teórica (científica) sobre o mundo em que vivemos. Está baseada na constituição psicológicas dos seres humanos e nas características essenciais da sua linguagem, principal ferramenta para se elaborar as teorias. E é neste momento em que adquirimos 0 aprendizado.

Atualmente, a abordagem evolucionista e os estudos de Neurociência buscam esclarecer a questão proposta por Quine, sobre a complexidade da mediação mental, por meio de pesquisas biológicas e neurológicas. A metodologia de Design proposta sob uma abordagem Biônica apresenta duas formas de desenvolvimento. Na primeira, parte-se de um problema e buscar suas soluções, com base na observação da dinâmica dos sistemas naturais, como plantas e animais (Fig. 4). A outra forma, entretanto, propõe 0 caminho inverso, ou seja, observa-se a natureza e, a partir das soluções que ela apresenta em determinado sistema animal ou vegetal, buscam-se a criação de um artefato, cuja utilidade será definida posteriormente (Fig. 4B).

\section{A Problema $\Rightarrow \begin{aligned} & \text { Observacáo } \\ & \text { da Natureza }\end{aligned} \Rightarrow$ Solução}

Metodologia da Biônica a partir do Problema

\section{Observaçáo
da Natureza $\Rightarrow$ Solução $\Rightarrow$ Problema}

Metodologia da Biônica a partir da Observaçăo de Soluçōes

Figura 4: Metodologias da Biônica.

Fonte: Costa et al., 2010.

Para Benyus (2010), outro enfoque pode ser dado ao se destacar três pontos referentes a Biomimética: a natureza como modelo; como medida; e, como mentora. 
Tabela 1: comparação da colher a partir das definições da Biomimética.

\begin{tabular}{|l|}
\hline \multicolumn{1}{|c|}{ Pontos da Biomimética } \\
\hline 1. A natureza como modelo. \\
A biomimética é uma nova ciência que estuda os modelos da natureza e depois \\
imita-os ou inspira-se neles ou em seus processos para resolver os problemas hu- \\
manos. \\
\hline 2. A natureza como medida. \\
A biomimética usa um padrão ecológico para ajuizar a “correção" das nossas inova- \\
ções. Após 3,8 bilhões de anos de evolução a natureza aprendeu: 0 que funciona. 0 \\
que é apropriado. 0 que dura. \\
\hline 3. A natureza como mentora. \\
A biomimética é uma nova forma de ver e valorizar a natureza. Ela inaugura uma \\
era cujas bases assentam não naquilo que podemos extrair da natureza, mas no \\
que podemos aprender com ela.
\end{tabular}

Fonte: Dos autores.

A Biomimética apresenta a natureza como "modelo", e o modelo é aquilo que serve para ser imitado, funciona como molde ou exemplo para os demais. Neste sentido é visível o papel da natureza como modelo, pois se partirmos da teoria evolucionista percebemos a transformação do homem, mediante e conjuntamente as transformações climáticas, terrestres e da natureza como um todo. 0 homem, como animal que é, aprendeu e aprende com a natureza, e o design se apropria dela para dar solução aos problemas da vida diária. Lidwell, Holden e Butler (2010) são claros ao colocar a contribuição de imagens da natureza para construção de ambientes segundo o Efeito Biofilia, gerando soluções menos estressantes e que proporcionam maior foco, atenção e concentração. Isso acontece graças ao processamento diferenciado do cortex pré-frontal humano com relação a imagens urbanas e imagens da natureza, sendo esta última mais profundamente enraizado no cérebro que no córtex cerebral, o que gera maior concentração no sujeito.

A natureza como "modelo" pode ser verificada ainda segundo o affordance, onde é visível na natureza que a forma segue a função, como no exemplo já dado da libélula. Pode-se verificar que a evolução do homem segue a natureza na medida em que ele compreende as propriedades dos elementos naturais e cria a partir deles. Designers tem a habilidade de estudar os elementos e juntando-os e transformando-os darem sentido aos objetos e produtos do mundo. Produtos robustos e fortes se ancoram em elementos da natureza que possuem estes valores, como metal, pedras, couro; objetos delicados se ancoram nas cores das flores, no som da água, na textura de folhas, no toque da pele de alguns animais.

A natureza como "medida" ensina o ser humano a obter soluções funcionais, apropriadas a sua espécie e duráveis. A natureza ensina isso a partir da funcionalidade das estruturas, sejam nas plantas onde cada estrutura tem sua função; nas organizações animais onde cada um tem o seu papel; na seleção natural de Darwin que acredita na adaptação e especialização dos seres vivos ou extinção; nas estações do ano e nas 
fases da Lua que se perpetuam, sempre duráveis. Estes conceitos, vindos da natureza, ancoram-se na ergonomia e usabilidade, conceitos amplamente utilizados pelos designers.

Para a International Ergonomics Association (2000, pg.1) ergonomia é a disciplina científica que trata da compreensão das interações entre os seres humanos e outros elementos de um sistema, compreende aspectos da antropometria, ou seja, das medidas do corpo humano, e da biomecânica, os estudos dos movimentos do corpo, com o objetivo de melhorar o rendimento e reduzir a sobrecarga das atividades do sujeito.

Segundo a ISO 9241 (2011) usabilidade é diretamente relacionada com a efetividade, eficiência e satisfação dos usuários em relação com os produtos. Essa abordagem pode ser traduzida, respectivamente, para alcance dos objetivos propostos, realização dos objetivos com destreza, e conforto. Jordan (1998) coloca que usabilidade é um conceito que diz respeito a grau de facilidade de uso de um produto, é um fator que depende do usuário, e por isso é intrinsecamente relacionado à interação entre um usuário, um produto e uma tarefa a ser realizada, por isso é dada relevância as características do usuário e do contexto de uso.

Jordam (1998) coloca ainda alguns pontos da usabilidade que promovem o conforto para o usuário, são eles: consistência, compatibilidade, feedback de usuário, clareza visual, clareza de operação, controle de usuário, prevenção e recuperação de erros, consideração dos recursos do usuário, apropriação da transferência de tecnologia, prioridade da funcionalidade e informação. Junto com os conceitos de ergonomia e usabilidade a natureza como "medida" ensina a realização de produtos funcionais, apropriadas à espécie e duráveis.

A natureza como "mentora" é aquela que ensina. É a natureza que nos dá os sinais da ação humana no planeta, responde á poluição, a degradação do solo, das matas e do mar e mostra a cada dia ao homem as consequências que pode sofrer se não cuidar de todas as formas de vida existentes. A natureza impulsiona os designers a desenvolverem novos materiais, reciclados, reutilizados, reaproveitados, e a partir dos problemas que são impostos, eles devem projetar de forma consciente e colaborar para mudança de mentalidade de consumo. A natureza como "mentora" ensina as ligas dos metais, os materiais que flutuam, os corantes naturais, os aromas das plantas, os processos de produção artesanal ou artificial daquilo que ela produz com maestria, e de forma natural.

\section{HISTÓRIA DOS UTENSÍLIOS DE COMER}

0 Naturalismo prega a observação da natureza, e olhando para ela percebe que há 3,5 milhões de anos surgiram mamíferos que caminhavam sob dois pés, os primeiros semelhantes aos homens.

Como colocado por Leal (1998), esta habilidade lhes proporcionou utilizar as mãos para retirar os caracóis das conchas, pegar frutas nas árvores e lançar-se sobre animais a fim de caçá-los. Esses homens primitivos já possuíam arpões, lanças com bicos envenena- 
dos, redes de pesca, arcos, flechas, armadilhas e graças a estes instrumentos deixaram de ser herbívoros e passaram a ser, também, carnívoros.

Foi observando a concha de moluscos (Fig. 5) que surgiram as primeiras colheres, que foram feitas, segundo Lopes (2007), de osso e pedra, e posteriormente de madeira e metal, sendo estas últimas utilizadas até hoje.
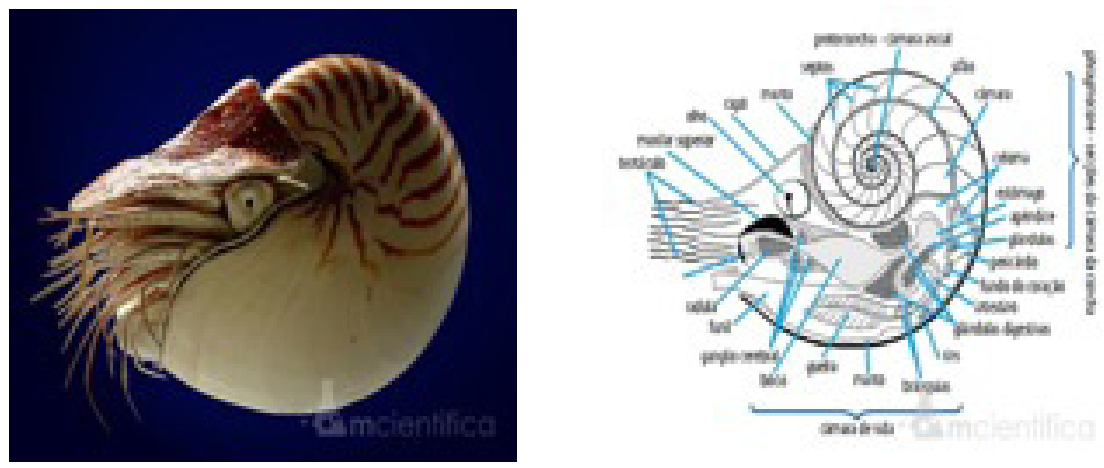

Fig. 5: Concha Nautilus

Fonte: Disponivel em: http://www.blog.mcientifica.com.br/o-nautilus/

Com o passar do tempo o homem descobriu o fogo, e este logo passou a assar a caça ou a pesca, para tanto foram desenvolvidos utensílios aproximados a espetos, para que a carne pudesse ser assada diretamente nas chamas ou brasas. Nesta época não havia utensílios precisos ou apurados, portanto o homem se utilizava das mãos para comer 0 alimento e em forma de concha, beber a água, procedimento feito até hoje na falta de copo ou recipiente que transporte líquidos (Fig. 6).

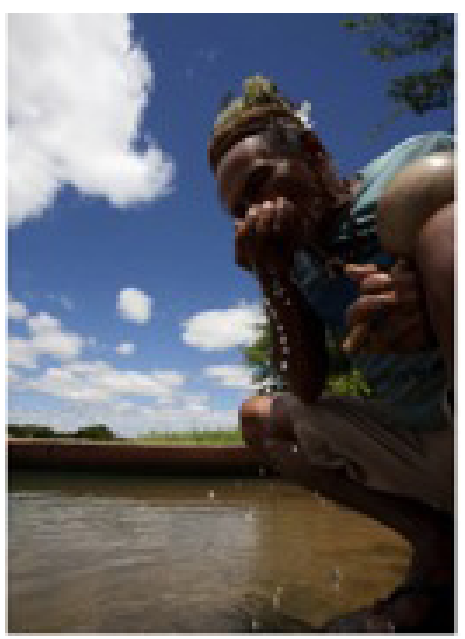

Fig. 6: Pessoa tomando água com a mão em forma de concha.

Fonte: Disponível em: http://www.oschicos.com.br/blog/?p=171

A partir do momento em que o homem se liga ao solo ele começa a estabelecer seus 


\section{Naturalismo e design: da mão à colher}

mobiliários, entre eles os que fazem parte do ato de preparar os alimentos e alimentar-se, desta forma armazenando o alimento.

Na Idade Média a tradição gastronômica vinha dos desenvolvimentos nos mosteiros, nos castelos haviam chefs, neste momento eram utilizados punhais para cortar a carne e frutas mas ainda se levava a comida à boca com a mão e os restos eram jogados ao chão para os cachorros.

Com base em Lopes (2007), podemos concluir que a colher surgiu antes de 79 d.C, pois neste ano ocorreu erupção do Versúvio, extinguindo a cidade de Pompéia, na antiga Itália, No século XIX quando as ruínas foram escavadas foram encontrados vestígios do que seria um suposto jogo de jantar de prata maciça, e este já continha uma colher de concha oval. Segundo Babitsch e Schiaffino (1998) nesta época a colher era utilizada para mexer e servir molhos do Império Romano, bem como para retirar os scargots das conchas.

\section{DA MÃO À COLHER}

A colher é um utensílio culinário utilizado por quase a totalidade dos povos na alimentação, para a degustação de cremes e sopas, mexer preparos, entre outras importantes funções na cozinha. É formada por uma parte côncava e uma pega. As colheres de mesa são geralmente de metal, enquanto que as de cozinha podem ser de metal, de madeira ou de plástico. Já o talher formado de um cabo e uma parte côncava, que serve para se tirar ou levar à boca os alimentos líquidos ou pouco consistentes.
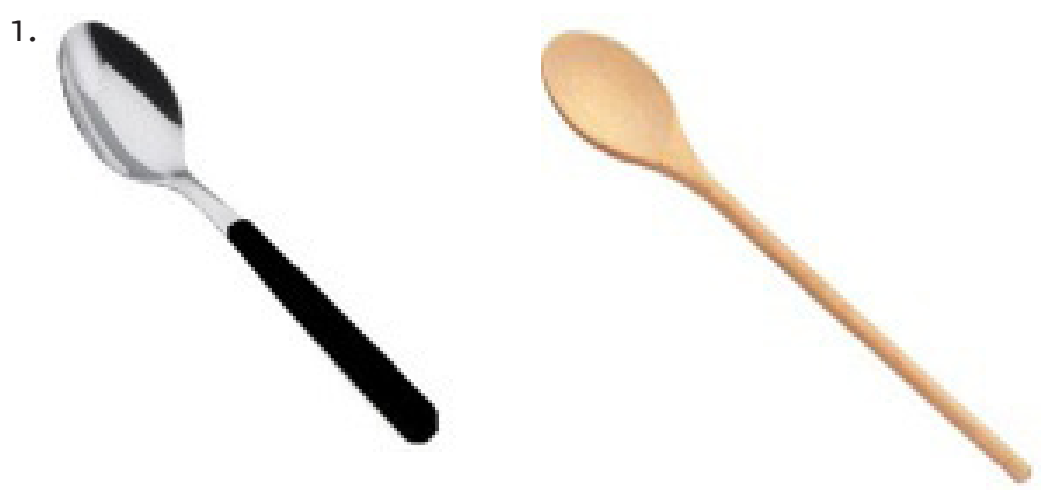

Fig. 11: Colher de inox e colher de pau.

Fonte: (1) Disponível em: http://homonimosparonimos.blogspot.com.br/

(2) Disponível em: https://twitter.com/search?q=\%23asianpunishments

Um dos campos de Design constitui uma concepção funcionalista, dito como "forma e função". Assim o formato de concha é a melhor concepção humana, até em tão, que atende as funções de alimentação, por exemplo. Segundo Ângela (2010) essa visão, de 
uma maneira geral, prioriza fatores racionais da relação entre homem e objeto, com relação aos aspectos de caráter sensorial.

Para Hume, a Filosofia era a ciência da natureza humana fundada no "indutivismo" e no "experimentalismo". Essa questão envolve o "princípio do Hábito", decorrente das crenças que desenvolvemos a partir da repetição de observações. 0 hábito de comer criou como consequência a colher.

A partir dos pontos de Benyus (2010), já citados neste artigo que destacam os três pontos referentes a Biomimética, traçou-se um paralelo com os aspectos da colher de acordo com cada ponto (Tabela 2).

Tabela 2: comparação da colher a partir das definições da Biomimética.

\begin{tabular}{|l|l|}
\hline \multicolumn{1}{|c|}{ Pontos da Biomimética } & \multicolumn{1}{c|}{ Exemplos referentes à colher } \\
\hline $\begin{array}{l}\text { 1. A natureza como modelo. } \\
\text { A biomimética é uma nova ciência que } \\
\text { estuda os modelos da natureza e depois } \\
\text { imita-os ou inspira-se neles ou em seus } \\
\text { processos para resolver os problemas } \\
\text { humanos. }\end{array}$ & $\begin{array}{l}\text { Observação da maneira como os animais } \\
\text { bebiam água fazendo uma concavidade } \\
\text { com a língua, associação com a concavi- } \\
\text { dade da concha onde ficava água, e uso } \\
\text { da concavidade da mãe, que posterior- } \\
\text { mente inspirou a criação da concavidade } \\
\text { da pá da colher. }\end{array}$ \\
\hline $\begin{array}{l}\text { 2. A natureza como medida. } \\
\text { A biomimética usa um padrão ecológico } \\
\text { para ajuizar a "correção" das nossas ino- } \\
\text { vações. Após 3,8 bilhões de anos de evo- } \\
\text { lução a natureza aprendeu: 0 que funcio- } \\
\text { na. 0 que é apropriado. 0 que dura. }\end{array}$ & $\begin{array}{l}\text { A parte de ergonomia da colher foi } \\
\text { baseada nas observações da estrutura } \\
\text { da mara ter uma melhor usabilida- } \\
\text { movimentos da língua, não machucar o } \\
\text { céu da boca, entrar e sair da boca sem } \\
\text { atrapalha a mastigação. }\end{array}$ \\
\hline $\begin{array}{l}\text { 3. A natureza como mentora. } \\
\text { A biomimética é uma nova forma de ver } \\
\text { e valorizar a natureza. Ela inaugura uma } \\
\text { era cujas bases assentam não naquilo } \\
\text { que podemos extrair da natureza, mas } \\
\text { no que podemos aprender com ela. }\end{array}$ & $\begin{array}{l}\text { Pode ser dito como análise dos materiais } \\
\text { utilizados na estrutura da colher. 0 metal } \\
\text { inoxidável, por exemplo, tem uma maior } \\
\text { durabilidade e resistência. A colher de } \\
\text { madeira tem a vantagem de não arranhar } \\
\text { o fundo das panelas, porém a desvanta- } \\
\text { gem de ficar com o cheiro de alguns ali- } \\
\text { mentos, como cebola e alho. A colher de } \\
\text { plástico é utilizada para colheres infantis } \\
\text { por não ter tanta força que pode agredir } \\
\text { a boca e dentes dos pequenos. }\end{array}$ \\
\hline
\end{tabular}

Fonte: Dos autores. 


\section{Naturalismo e design: da mão à colher}

\section{CONSIDERAÇÕES FINAIS}

Percebe-se que a aproximação entre Naturalismo e Design se dá ao passo em que natureza e cultura se unem, seja para resolver problemas de cunho social, como instituição de utensílios que favoreçam a vida em sociedade, ou na busca de soluções das mais variadas, a partir da observação da natureza, seja ela na criação a partir da semelhança, causa e efeito ou contiguidade, fazendo uso de técnicas como a Biomimética, Biodesign e Biônica.

A Biomimética toma a natureza como modelo, medida e mentora das transformações. 0 Biodesign é o farol que guia o projeto e a Biônica é o que propõe soluções simples, econômicas e ecoeficiêntes. Os três termos dizem respeito a soluções com base nas concepções Naturalistas.

Essa consideração indica a natureza como responsável, inclusive, pela produção cultural, que se desenvolveu pelas mentes e mãos dos homens. Portanto, assumir os sistemas naturais como modelos para as produções culturais é propor um processo de aproximação entre duas etapas de um mesmo processo evolutivo." (COSTA et al., 2010)

A colher, nosso objeto de estudo, demonstra perfeitamente este ponto. Do uso da mão ao desenvolvimento da ferramenta, todo o processo de aprendizado acontece de forma natural. E o design entra como colaborador no processo da constante evolução através das técnicas da Biônica. 


\section{REFERÊNCIAS}

> BABITSCH; SCHIAFFINO. In punta di forchetta. Milão: Idealibre, 1998.

> BATISTA, Robe. Biodesign. Disponível em: http://www.revistacliche.com.br/2013/02/ luigi-colani/ Acessado em: 09 junho de 2013.

> BENYUS, Janine M. Biomimética: Inovação inspirada pela natureza. 6š ed. São Paulo: Editora Cultrix, 2011.

> COSTA, Angela; NUNES, Juliane; BORTALATO, Márcia; SOUZA, Richar. Design e naturalismo: filosofia naturalista, biônica e ecodesign. Design, Arte, Moda e Tecnologia. São Paulo: Rosari, Universidade Anhembi Morumbi, PUC-Rio e Unesp-Bauru, 2010. 10 pgs.

> DUTRA, Luiz Henrique de Araújo. Oposições Filosóficas. Florianópolis: Editora da UFSC, 2005.

> FLANDRIN, Jean-Louis; MONTANARI, Massimo. História da alimentação. 6. ed. São Paulo: Estação Liberdade, 1998. 885p.

> International Ergonomics Association. San Diego, USA, 2000.

> ISO (1998). ISO 9241-11: Ergonomic requirements for office work with visual display terminals (VDTs). Part 11: Guidelines for specifying and measuring usability. Gènève: International Organisation for Standardisation.

> JAPIASSÚ, Hilton; MARCONDES, Danilo. Dicionário Básico de Filosofia. Rio de Janeiro, 2001.

> JORDAN, Patrick. An Introduction to usability. Londres: Taylor đt Francis, 1998. 10 pgs.

> LAKATOS, Eva; MARKONI, Marina. Metodologia no Trabalho Científico. $7^{\circ}$ Ed. São Paulo: Atlas, 2007. 225 p.

> LEAL, Maria Leonor de Macedo Soares. A história da gastronomia. Rio de Janeiro: SENAC, 1998. 144 pg.

$>$ LIDWELL, William; HOLDEN, Kritina; BUTLER, Jill. Universal Principles of Design. Estados Unidos: Rockport, 2010. 272 pgs.

$>$ LOPES, J. A. Dias. A rainha que virou pizza. São Paulo: Companhia Editora Nacional, 2007. $367 \mathrm{pg}$.

> MOURA, Leonel. Biodesign, o design do vivo. Jornal de Negócio de Portugal, 2011. Disponível em: http://www.designbrasil.org.br/noticias/biodesign-o-design-do-vivo\#. UbmalfmTj51. Acessado em: 09 de junho de 2013.

$>$ OLIVEIRA, Monique. Design de superfície: proposta de procedimento metodológico para criação de estampas têxteis com referência em elementos naturais. Dissertação do curso de Metrado em Design do Programa de Pós-Graduação em Design: Universidade Federal do Rio Grande do Sul, 2012 
> PATARRANA, Manuel. Design sustentável. In: BCSD. Portugal, n. 10, Março, 2007. Disponivel em: http://www.bcsdportugal.org/files/1022.pdf. Acessado em: 10/06/2013.

> SILVA, Lucielem Chequim da. 0 Design de equipamentos de tecnologia assistiva como auxílio no desempenho das atividades da vida diária de idosos e pessoas com deficiência, socialmente institucionalizados. Dissertação de mestrado apresentada no programa de pós graduação em Design da Escola de Engenharia da Universidade Federal do Rio Grande do Sul. Porto Alegre, 2011.

\section{Bruna Brogin}

brunabrogin@hotmail.com

Richard Perassi Luiz de Souza, Doutor em Comunicação e Semiótica (PUC/SP/2001) e professor do curso de graduação em Design e dos programas de pós-graduação em Design e Expressão Gráfica (Pós-Design/UFSC) e Engenharia e Gestão do Conhecimento (PPECC/UFSC)

richard.perassi@uol.com.br

\section{Sharlene Melanie}

sharlene.melanie@gmail.com

Túlio Henrique Mandolesi Sá

tulio@floripa.com.br

Vilson João Batista

vbatista19@gmail.com 